\title{
Gliding into diapause: early embryo development in roe deer (Capreolus capreolus)
}

\author{
B Drews ${ }^{1}$, SE Ulbrich ${ }^{1}$, A Rudolf Vegas ${ }^{1}$, K Jewgenow ${ }^{2}$, J Zahmel ${ }^{2}$, K Roellig ${ }^{2}, S$ \\ Ortmann ${ }^{2}$, TB Hildebrandt and F Goeritz ${ }^{2}$ \\ ${ }^{1}$ Institute of Agricultural Sciences, ETH Zurich, Switzerland \\ ${ }^{2}$ Leibniz Institute for Zoo- and Wildlife Research, Berlin, Germany
}

Corresponding author email: barbara.drews@usys.ethz.ch

\begin{abstract}
During mammalian diapause, the embryo is arrested at the blastocyst stage. In diapausing carnivores and marsupials, growth arrest of the blastocyst is coincident with a quiescent corpus luteum (CL). In the roe deer, progesterone is produced throughout diapause and the blastocyst exhibits very slow growth. To date, early roe deer embryos of known age have not been described. Therefore, it is not known at which stage and at what pace the roe deer embryo enters diapause. To collect multiple embryos of known gestational age, we performed cycle synchronization and superovulation in captive roe deer prior to artificial insemination (AI) and natural breeding (NB), respectively. Superovulatory responses were evaluated based on ultrasonographic detection of $\mathrm{CL}$ formation on the day of in vivo embryo flushing and on plasma progesterone (P4) analysis. In total, 33 superovulation treatments resulted in $6.6 \pm 2.2$ (mean \pm SD) CL per doe on the day of embryo flushing. At days 6 and 7 after Al, 37 multicellular embryos up to the morula stage were retrieved from 8 does. At day 12 and 13 after natural breeding, 28 embryos, mainly at the blastocyst stage $(n=20)$, were collected from 7 does. Multiple embryos could be collected from single animals, proving the feasibility of superovulation in this species. Compared to other diapausing and non-diapausing species where blastocysts have formed at days $6-8$, roe deer embryo development appeared to be already decelerated prior to the blastocyst stage. The roe deer might therefore be well suited as a model to investigate mechanisms regulating embryonic growth velocity with respect to cell cycle control.
\end{abstract}

\section{Introduction}

Early mammalian pre-implantation development begins with the first cell divisions in the course of cleavage. The pace of mitosis during that phase is under the control of maternal mRNA and proteins stored in the cytoplasm. Coincident with the activation of the embryonic genome, the cell cycle lengthens [1] and cells begin to differentiate during blastocyst formation and gastrulation [2, 3].

In cattle, which belong to the order Ruminantia like the roe deer, a blastocyst with a diameter of around $180 \mu \mathrm{m}$ forms within 6 days $[4,5]$. The time period needed to reach the blastocyst stage in diapausing carnivore and marsupial species is comparable with non-diapausing species. In the tammar wallaby and in the mink for example, a blastocyst with a diameter of around $200 \mu \mathrm{m}$ has likewise developed 6 to 7 days after ovulation [6-9].

In the monoestrus roe deer, mating takes place in July and August. After fertilization, the embryo develops to the blastocyst stage where further development is extremely decelerated and 
blastocyst diameter increases only slowly [10]. In the period between November to December the embryo resumes a more rapid growth, elongates and finally implants [11, 12]. Between May and June, the doe then gives birth, usually to a twin offspring.

There are numerous descriptions of embryos retrieved from hunted roe deer in the period of diapause, reactivation and elongation between October and December [11, 13-16].

In contrast, descriptions of the very early roe deer embryo, presumptively prior to diapause, are extremely scarce and historic. One important documentation dating back as far as 1854 is from Bischoff, who, in his own words, "... with expenditure of much time and effort and an unspeakable, truly stupid patience, searched almost all years numerous roe deer uteri in the last ten years in these months to find the eggs. I have set all possible methods to the application (...), but almost always in vain."[17]. It is thanks to the persistent scientific diligence of Bischoff that we have reports of roe deer embryonic stages in the oviduct. In August he recovered three pre-morula stages from the oviduct and another multicellular stage from the uterus. While he was not successful in finding embryos in the months of September and October, he recovered uterine blastocyst stages in November and December. In agreement, Keibel [18] recovered two uterine morula stages within their zonae pellucidae in late August. Moreover, he was also able to collect a fair number of blastocysts in October $(n=14)$ and November $(n=34)$. These blastocysts were mostly collapsed and were all devoid of a zona pellucida. Diameters ranged from 0.70 to $1.46 \mathrm{~mm}$ in October and 1.10 to $2.30 \mathrm{~mm}$ in November, demonstrating slow growth during diapause. Keibel reported the beginning of gastrulation and embryonic disc formation during this period. In December, he collected two more embryos, one of which had already reached a length of $3.3 \mathrm{~mm}$ and was in the process of elongation in the typical ruminant fashion.

In diapausing carnivores and marsupials, resumption of mitotic activity and development beyond the early blastocyst stage is dependent on luteal progesterone synthesis. While progesterone alone does not activate the blastocyst, it is involved in a downstream signaling cascade which finally triggers uterine secretions responsible for upregulation of blastocyst growth [19-21]. Luteal progesterone production in mustelids and marsupials is regulated at different hormonal levels: photoperiod stimulates prolactin synthesis in the anterior pituitary following reduction in pineal melatonin. Prolactin then modulates luteal progesterone production. During diapause, luteal progesterone production has ceased. The blastocyst remains within its zona pellucida and mitotic activity is virtually absent [22-24]. Only after resumption of luteal function, the progesterone primed endometrium facilitates exit from diapause resulting in rapid embryonic growth, embryonic disc formation $[24,25]$ and subsequent implantation within a short time window $[21,26]$.

Renfree et al. [27] defined three stages of embryonic diapause, which specifically apply for carnivore and marsupial species: entry into diapause and arrest of cell division, maintenance of diapause without mitotic activity and reactivation of development and embryo growth. For the roe deer, and possibly the nine banded armadillo [28], the definition of these stages requires amendment. The persistence of an active corpus luteum, loss of the zona pellucida and decelerated but nevertheless detectable embryonic growth $[12,16]$ accompanied by mitotic activity during the period of diapause $[12,16,18]$ set the roe deer apart from the marsupial and carnivore model, where diapause also occurs as a regular reproductive feature.

The historic description of the early roe deer embryonic stages lacked knowledge of their age. Therefore, it cannot be established when the roe deer embryo actually enters diapause, and if so, at which pace the deceleration of the cell cycle and embryonic growth occurs. Although many authors have stated that the roe deer embryo enters diapause at the blastocyst stage, evidence for support of assumption is missing to date.

To overcome the difficulty of single observations derived of animals with unknown mating history, we cycle synchronized and superovulated captive does and performed embryo flushing on defined 
days of pregnancy. Hormonal treatment was adopted from protocols in cattle and deer. The response to the treatment protocol was evaluated on the formation of corpora lutea on the day of $\mathrm{Al}$ and on the day of embryo flushing as seen by ultrasound. Early embryo stages collected in vivo on days 6, 7, 12 and 13 are described and their development is compared to embryo development of other species exhibiting diapause and closely related species not exhibiting diapause such as deer and cattle.

\section{Materials and methods}

\section{Animals}

The animal experiments conducted during this trial concurred with the German Animal Welfare law requirements and to the guidelines of the Internal Committee of Ethics and Animal Welfare of the Leibniz Institute for Zoo and Wildlife Research (approval number 2347-25-2014).

All roe deer were maintained at the field research station of the Leibniz Institute for Zoo- and Wildlife Research, Berlin, Germany. The does were kept in enclosures (800 to $1800 \mathrm{~m}^{2}$ ) in stable groups of two to five animals. The animals could feed on grass and browse and were additionally given pelleted compound feed (Märka KA-18-3, Märkische Kraftfutter GmBH, Guben, Germany). Hay and water were provided ad libitum.

A total of 19 does were included in the study which comprised of cycle synchronization, superovulation, artificial insemination (AI) or natural breeding (NB) and embryo flushing.

\section{Capture, immobilisation and anaesthesia}

For handling, animals were guided groupwise ( 3 to 4 animals) via an alley system from their enclosures to a small, narrow and darkened compartment. This compartment was attached to two aligned restraint boxes where animals were individually treated. The darkened compartment was connected to the restraint boxes by a trap door which was handled from the outside of the compartment. As soon as the animals had entered the restraint boxes, the trapdoor was closed.

Intramuscular injections were administered manually in the restraint box. In the case of hormone injections, animals were subsequently released to their respective enclosures by opening the front of the restraint boxes. If animals had to be put under general anesthesia (for insertion/removal of drug releasing device, artificial insemination, embryo flushing) they received an intramuscular (i.m.) injection of $0.06 \mathrm{mg} / \mathrm{kg}$ body mass Medetomidin (Domitor ad us. vet. Pfizer, Berlin, Germany) combined with $5 \mathrm{mg} / \mathrm{kg}$ body mass Ketamin (Ketamin 10\%, Selectavet, Weyarn-Holzolling, Germany). For further veterinary interventions animals were transferred to an examination room where they were placed in lateral recumbency on a surgical table.

After completion of short termed procedures (insertion/removal of drug releasing device, artificial insemination), each animal was transported back into its enclosure. Here, the effect of medetomidin was reversed by i.m. injection of atipamezole (Antisedan, Zoetis, Berlin, Germany; 5fold dosage of the administered medetomidine).

In the case of surgical embryo flushing, the injection anesthesia was prolonged by inhalation anaesthesia with isoflurane (1.5 - 5 Vol \% Isofluran in 1.5 I Oxygen/min, CP_Pharma, Burgdorf, Germany) delivered via a cuffed, $5.5 \mathrm{~mm}$ wide endotracheal tube. During the surgery, the animal received $0.02 \mathrm{mg} / \mathrm{kg}$ body mass Butorphanol i.v. (Dolorex, Intervet, Oberschleissheim, Germany) and just prior to completion of the surgery $0.2 \mathrm{mg} / \mathrm{kg}$ body mass meloxicam (Metacam, BoehringerIngelheim, Ingelheim, Germany) one fifth of the dosage i.v and the remaining dosage s.c.. After treatment, the endotracheal tube was removed and the animal was transferred back to its enclosure. If necessary, medetomidine effects were antagonized as described above. 


\section{Cycle synchronization and superovulation}

All does were cycle synchronized and superovulated during the physiological breeding season (mid July to beginning of August). The day of Al and the first day of NB was defined as day 0 . According to the respective outcome, the treatment protocols were modified leading to slight differences between 2014, 2015 and 2016. However, the basic principle of the programme were based on ovulation inhibition via progesterone analogues, superstimulation of follicular growth and in some cases induction of ovulation followed by Al and NB, respectively. The synchronization protocols are schematically depicted in Fig. 1.

In 2014, cycle synchronization of $n=7$ does began with the insertion of an intravaginal sponge containing a progesterone analogue (40 mg Flugestonacetat, Chronogest, Intervet) on day -16 . The growth of multiple follicles was stimulated by an i.m injection of equine chorionic gonadotrophin (eCG, 1000 I.E. i.m., Intergonan 240 I.E./ml, MSD Animal Health, Germany) on day -8. The intravaginal sponges were removed 3 days later (day -5 ). Ovulation was induced by human chorionic gonadotrophin (hCG, 1500 I.E., i.m. Ovogest 1000 I.E./ml, MSD Animal Health, Germany) on day -2 . Al was performed on day 0 , followed by embryo flushing on day 6 ( 3 does) and 7 ( 2 does), respectively.

In 2015, $n=13$ does were randomly divided in two groups ( $n=6$ and 7, respectively). Inhibition of ovulation was achieved in both groups by subcutaneous insertion of a flexible progestin releasing rod at the base of the ear (Etonogestrel $68 \mathrm{mg}$, Implanon, MSD, Germany) on day -29. In group 1, follicular growth was stimulated by eCG (1000 I.E. i.m., Intergonan 240 I.E./ml, MSD Animal Health, Germany) during implant removal on day 3. In group 2, intramuscular injection of eCG was performed on day -7 , prior to implant removal on day -5 . Both groups received hCG (1500 I.E. i.m., Ovogest 1000 I.E./ml, MSD Animal Health, Germany) on day 2, Al was performed on day 0 and embryo flushing on day 7. Due to the poor results of the embryo flushing of the first 3 does of group 2, the 4, remaining does of this group were not flushed.

In 2016, $n=16$ does received one half of a progestin releasing rod placed under the skin at the ear base (Etonogestrel $68 \mathrm{mg}$, Implanon, MSD, Germany) on day -11. During implant removal on day -2, the does received eCG (1000 I.E. i.m., Intergonan 240 I.E./ml, MSD Animal Health, Germany). To optimize the time point of fertilization in order to gain as many embryos as possible, does were bred naturally in 2016. For this purpose, one proven male breeder was introduced to each of the doe groups one day after implant removal. The day of the first observed mating was defined as day 0 . Embryo flushing was performed on days 12 and 13 , respectively.

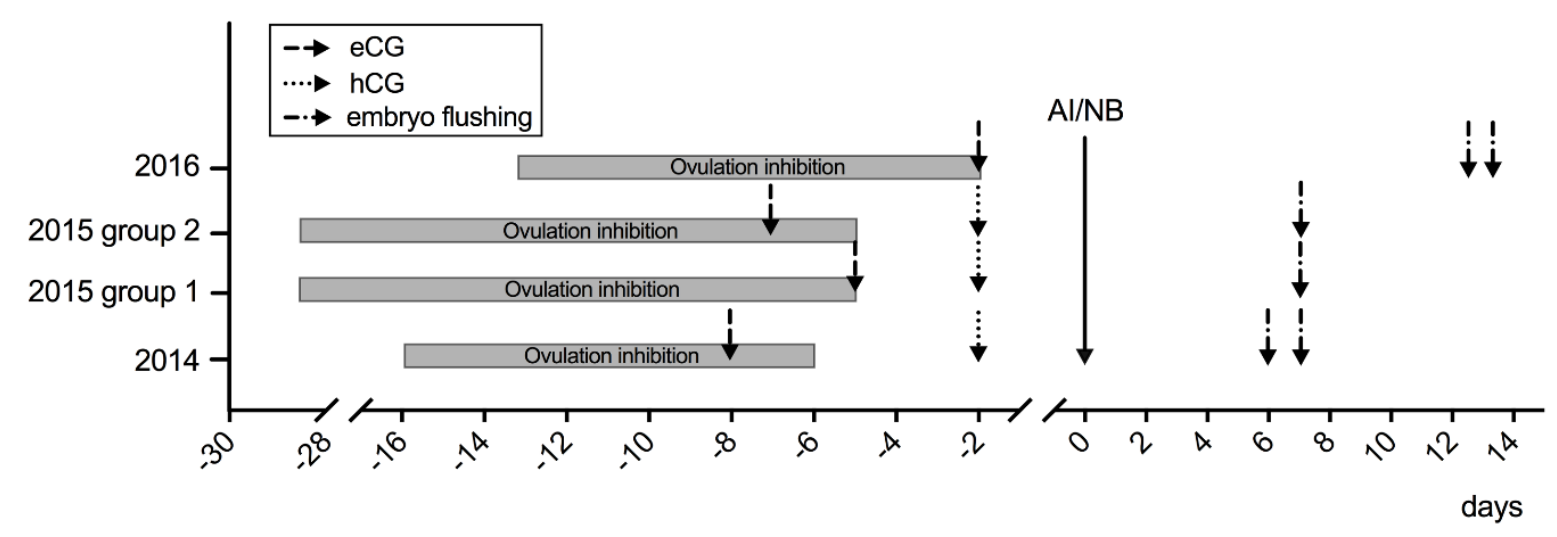

Figure 1 Schematic overview of oestrus cycle synchronization, superovulation, and embryo flushing. Ovulation inhibition was performed using an intravaginal or subcutaneous progestin releasing device, respectively. eCG - equine chorionic gonadotropin, hCG - human chorionic gonadotropin; Al - artificial insemination, NB natural breeding. 


\section{Ultrasound examination and blood sampling}

Ultrasound examinations (US) and blood collection were performed whenever animals were under general anesthesia (e. g. for the purpose of insertion and removal of hormone implants, artificial insemination, embro flushing). For transcutaneous US (Esaote MyLab, 28MHz, Esaote, Genua, Italy) the fur was completely shaved in the inguinal region and ultrasound gel was applied before systematically scanning the reproductive tract. Ovarian structures such as $\mathrm{CL}$ and follicles were displayed and video loops were stored for retrospective analysis. Blood was collected from the jugular vein in tubes $(7.5 \mathrm{ml})$ containing serum gel (S-Monovette, Sarstedt, Nuernbrecht, Germany). Blood samples were centrifuged at $2000 \mathrm{~g}$ for $15 \mathrm{~min}$ and stored at $-20^{\circ} \mathrm{C}$ for later analysis.

\section{Semen collection}

Semen collection was performed by electroejaculation as described by Goeritz et al. [29].

\section{Artificial insemination (AI)}

For Al, an insemination pipette ( 7 french) was introduced into the vagina, gently manipulated through the cervix and placed in the uterine body. The correct position of the pipette was confirmed by transabdominal US. Each doe received a total volume of $2 \mathrm{ml}$ ejaculate adjusted to a concentration of $150 \times 10^{6}$ spermatozoa per ml (cell culture medium M199, Sigma, Deisenhofen, Germany).

\section{Mating observation}

In 2016, one day after implant removal, two to three does were socialized with one breeding partner. Animals were observed with binoculars from elevated platforms installed outside the enclosure and mating events were recorded. The does were distinguished by their earmarks. The natural cover or the enclosures inhibited the full sight of the whole area, so that not all animals could be observed at all times. Mating observations were performed starting with sunrise at 4 AM to $7 \mathrm{AM}$ and at twilight from 5 PM to sunset at $10 \mathrm{PM}$. Sporadic observations were performed in between, however the animals tended to stay inactive and hidden during the heat of the day.

\section{Surgical Embryo flushing}

Surgical embryo flushing was performed on days 6 and 7 in 2014 and 2015 and on days 12 and 13 in 2016. In preparation for the surgery, the skin in the area of the udder was shaved and washed= For the planning of the surgical intervention, the reproductive tract was imaged by US (Esaote MyLab, $28 \mathrm{MHz}$, Esaote, Genua, Italy) for. The uterine horns and ovaries were exteriorized manually via a 5 $-8 \mathrm{~cm}$ long incision in the linea alba. Each horn was flushed separately. After blunt perforation of the tip of the uterine horn with an irrigation canula, a total of $25 \mathrm{ml}$ flushing medium per uterine horn (Equiflush with PVA, Minitueb, Tiefenbach, Germany) was introduced and recovered via a Foley ballon catheter ( $\mathrm{CH} 8,24 \mathrm{~cm}$, Minitueb, Landshut, Germany) inserted at the basis of the uterine body. The perforation was closed with a single knot suture. The reproductive tract was placed back in the abdominal cavity and the abdominal wall was closed by surgical suture.

\section{Morphological evaluation of collected embryos}

The retrieved flushing medium was scanned for embryos under a stereo microscope (SteREO Discovery.V8, 1:8 Zoom rate, Zeiss, Feldbach, Switzerland). Embryos were staged and classified according to Gardner et al. [30] and Baczkowski et al. [31]. In brief, embryos with up to 16 cells were scored concerning number of blastomeres, equality of cell size and grade of fragmentation. Morulae are difficult to assess due fundamental structural changes and compaction. They were therefore only classified as morula stage. Blastocyst quality was determined by evaluating the number and connection of embryoblast and trophoblast cells, degree of expansion and hatching. 


\section{Progesterone analysis}

Plasma progesterone (P4) was determined by a competitive enzyme-linked immunosorbrnt assay (ELISA) according to Prakash et al. [32] and described in detail in Drews et al. [33] (antibody as kind courtesy by Franz Weber, LMU Munich, Oberschleissheim, Germany, and 4-pregnen-3,20-dione-3O-carboxymethyloxime horseradish peroxidase as tracer) . [33]. Briefly, the steroid hormones were extracted from $500 \mu \mathrm{l}$ plasma with $5 \mathrm{ml}$ tert. butylmethylether/ petrol ether (30/70) (AppliChem, Panraec, ITW Companies) in an extraction glass prior to analysis. The ELISA was performed in a 96well microtiter plate reader (Cytation 3 cell imaging multi-mode reader, BioTek). The tracer and antibody dilution were $1: 11000$ and 1:210 000 respectively. The limit of quantification was at 0.09 $\mathrm{ng} / \mathrm{ml}$ and, the inter-assay and intra-assay variation were $11 \%$ and $7 \%$ respectively.

\section{Statistical analysis}

Statistical analysis was performed using Prism (Prism 7, GraphPad Software Inc., La Jolla, USA). Normal distribution of the P4 concentrations were tested by D'Agostino \& Pearson and ShapiroWilk test. To test for differences in plasma P4 concentrations between the day of Al and the day of embryo flushing in 2014 and 2015, Wilcoxon patched-pairs signed rank test was performed. To test for the difference in plasma P4 concentrations at the day of $\mathrm{Al}$ in does where embryos were collected versus does were no embryos were recovered, Student's unpaired t test was used.

\section{Results}

\section{Superovulation response}

The superovulation response following the hormonal treatments was evaluated based on the number of $\mathrm{CL}$ as displayed by ultrasound at the day of $\mathrm{Al}$ and at the day of embryo flushing and on plasma progesterone concentrations. The plasma progesterone concentrations were low at the time of implant insertion and had increased by the day of Al (Fig. 2).

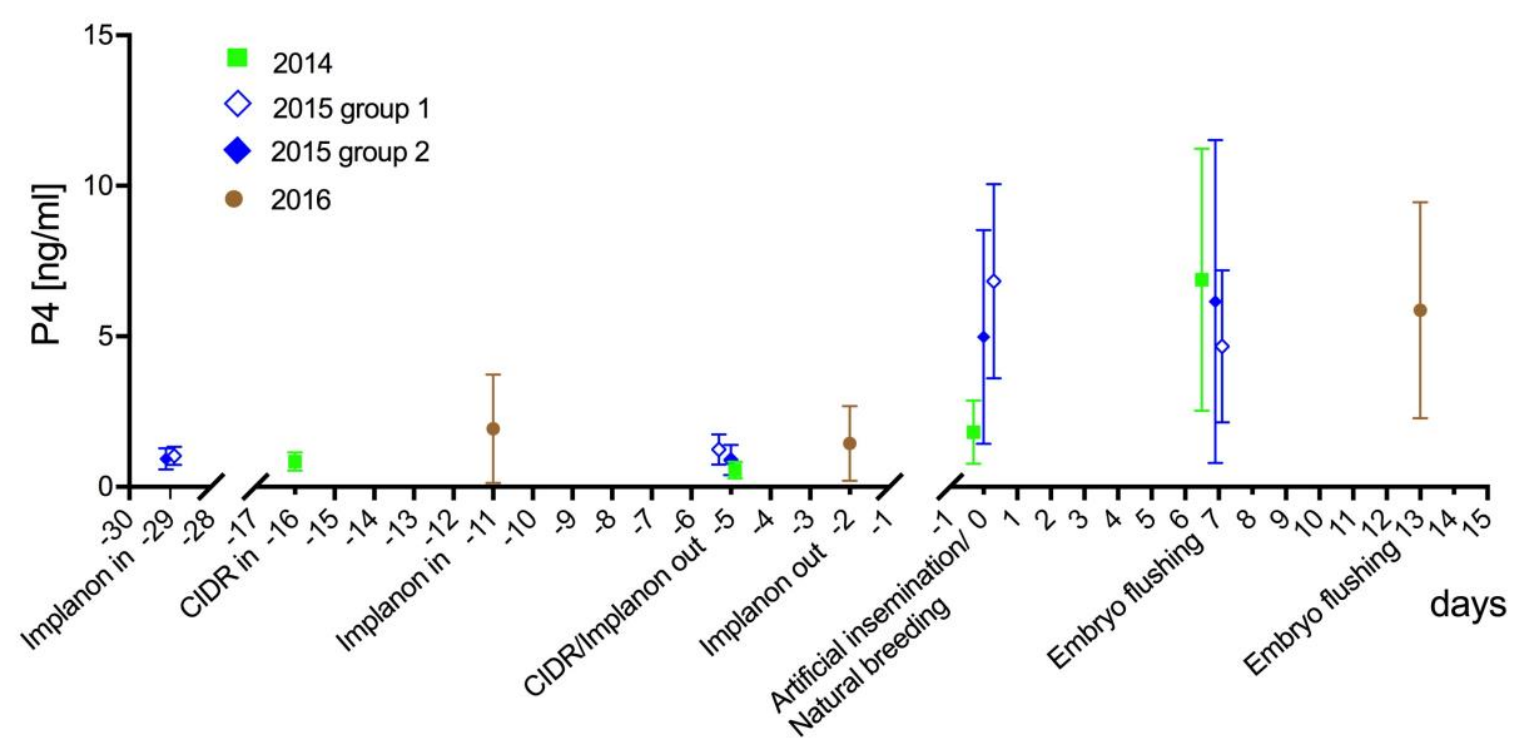

Figure 2: Treatments and corresponding progesterone (P4) concentrations. The day of artificial insemination is defined as day 0 . In case of natural breeding, day 0 refers to the first observed mating one day after implant removal. CIDR - controlled internal drug release (Flugestonacetat), intravaginal application; Implanon (Etonogestrel) subcutaneous application; green squares - treatments in 2014, filled blue diamonds treatments 2015 group 1, empty blue diamonds - treatments 2015 group 2, brown circles - treatments 2016; mean \pm SD. 
At the day of $\mathrm{Al}$, the average progesterone concentration of the does inseminated in 2014 and in 2015 (group 1) was $3.64 \pm 3.55 \mathrm{ng} / \mathrm{ml}(\mathrm{n}=14)$. Compared to the animals inseminated in 2014 and to group 1 in 2015, group 2 in 2015 had higher plasma progesterone concentrations $(6.83 \pm 3.25$ $\mathrm{ng} / \mathrm{ml} ; \mathrm{n}=6$ ) at the day of $\mathrm{Al}$ (nonsignificant), indicating that the timing of Al was too late for successful fertilization. This observation is underlined by the fact that significantly more embryos $(p=0.02)$ could be collected from animals where P4 values were lower at the day of Al compared to the day of embryo flushing (Fig. 3)

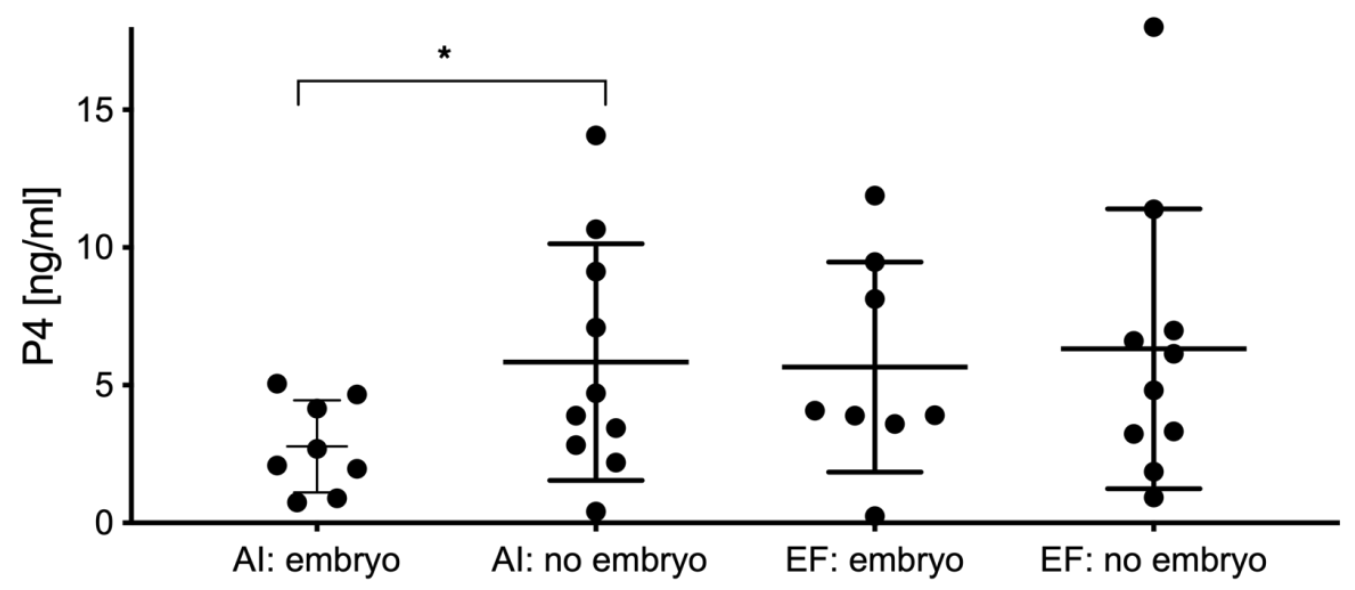

Figure 3: Plasma progesterone (P4) concentrations at the day of artificial insemination (AI) and embryo flushing (EF) of does from which embryos could be collected (embryo) and of does from which no embryos (no embryo) could be collected at EF. The asterisk indicates a significant difference $(p=0.02)$.

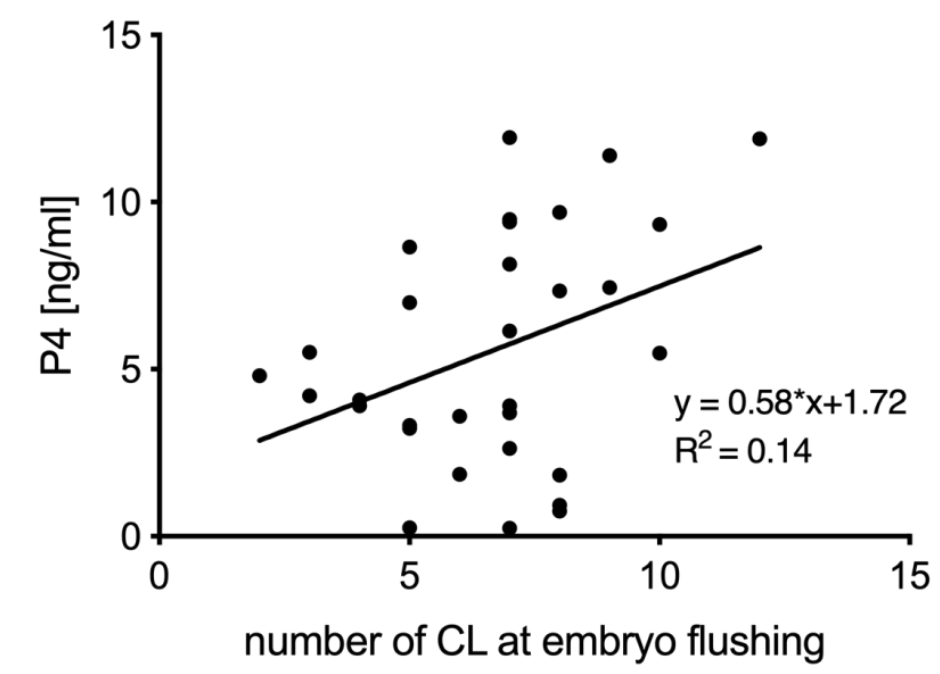

Figure 4. Relationship between number of corpora lutea $(\mathrm{CL})$ and plasma progesterone (P4) concentrations at the day of embryo flushing (years 2014, 2015, 2016), $p=0.04$.

\section{Embryo collection}

At day 6 and 7 in 2014 and 2015, 37 multicellular embryos up to the morula stage were retrieved from 8 does after Al (Tab. 1). In 2015, no embryos were recovered from 4 does of group 2 . The two does of group 1 in 2015 that were not flushed after treatment due to the negative expected outcome did not give birth to a fawn in the following spring.

On the day of embryo flushing, the average plasma progesterone concentration of the does in 2014, 2015 and 2016 was $6.0 \pm 4.0 \mathrm{ng} / \mathrm{ml}(\mathrm{n}=33)$. The superovulated does displayed on average 6.6 $\pm 2.2 \mathrm{CL}$ on the day of embryo flushing (EF) $(n=33)$. The number of $C L$ significantly $(p=0.04)$ correlated with plasma progesterone concentrations (Fig. 4). 
From does that developed additional $\mathrm{CL}$ between the day of $\mathrm{Al}$ and the day of embryo flushing, significantly more embryos were collected ( 35 embryos from 5 does with additional $\mathrm{CL}$ development versus 2 embryos from 2 does with no additional $C L$ development, $p=0.02$ ). This finding correlated to significantly $(p=0.02)$ lower progesterone concentrations at the day of $A l$ in does from which embryos were collected $(n=8$, average P4 concentration $=2.8 \pm 1.7 \mathrm{ng} / \mathrm{ml}$ ) in comparison to does from which no embryos were collected $(\mathrm{N}=10$, average $\mathrm{P} 4$ concentration $=6.5 \pm$ $4.0 \mathrm{ng} / \mathrm{ml}$ ) (Fig. 3). In the latter, the timing of the day of Al was probably too late.

To test if the embryos collected after hormonal treatment were developmentally competent to proceed to the blastocyst stage, embryo flushing was also performed at a later stage, i.e. on days 12 and 13 after NB in 2016. Here, a total of 28 embryos was collected from 7 does (Tab. 2). Of those embryos, 20 were at the blastocyst stage, still within their zonae pellucidae. One blastocyst was in the process of hatching and one blastocyst had hatched.

Table 1. Embryonic stages collected on days 6 and 7 after artificial insemination in 2014 and 2015. UFO - unfertilized oocyte

\begin{tabular}{|c|c|c|c|c|c|c|}
\hline Animal & Year & UFO & $\begin{array}{l}2-4 \\
\text { cell }\end{array}$ & $\begin{array}{l}5-8 \\
\text { cell }\end{array}$ & 12 -cell & $\begin{array}{c}\text { Total } \\
\text { embryos } \\
\text { per doe }\end{array}$ \\
\hline 1 & 2014 & 1 & - & - & 1 & 1 \\
\hline 2 & 2014 & 3 & 1 & - & - & 1 \\
\hline 3 & 2014 & - & 4 & 1 & - & 5 \\
\hline 4 & 2014 & 9 & - & - & - & - \\
\hline 5 & 2015 & - & - & - & - & - \\
\hline 6 & 2015 & - & 5 & - & - & 5 \\
\hline 7 & 2015 & - & - & 1 & - & 1 \\
\hline 8 & 2015 & - & 4 & 1 & - & 5 \\
\hline 9 & 2015 & 3 & 15 & 3 & - & 18 \\
\hline 10 & 2015 & 1 & 1 & - & - & 1 \\
\hline 11 & 2015 & 14 & - & - & - & - \\
\hline 12 & 2015 & 3 & - & - & - & - \\
\hline 13 & 2015 & 1 & - & - & - & - \\
\hline 14 & 2015 & 1 & - & - & - & - \\
\hline 15 & 2015 & 1 & - & - & - & - \\
\hline 16 & 2015 & 1 & - & - & - & - \\
\hline 17 & 2015 & 0 & - & - & - & - \\
\hline 18 & 2015 & 0 & - & - & - & - \\
\hline Total & & 38 & 30 & 6 & 1 & 37 \\
\hline
\end{tabular}




\section{Discussion}

All applied hormone treatments resulted in multiple ovulations and subsequent development of CL. The superstimulatory response in the roe deer was thus comparable to that reported for other deer species such as brown brocket deer (Maraza nemorivaga) (mean ovulation rate 7.0 [34]), red deer (Cervus elephas) (mean ovulation rate 8.8 [35]) and fallow deer (Dama dama)(mean ovulation rate $8.3[36])$.

There was no significant difference between the different protocols regarding the number of stimulated ovulations on the day of Al. However, in animals that developed additional CL between the day of $\mathrm{Al}$ and the day of embryo flushing, more embryos were collected. These findings suggest that ovulation of group 2 in 2015, where no embryos were collected, ovulation had already taken place a few days prior to Al. Retrospectively, the therefore late timing of Al resulted in a negative outcome of fertilization and subsequent lack of recovered embryos of group 2 .

The temporal relationship between implant removal, estrus, LH surge and ovulation is unknown in roe deer. In other cervid species, e.g. red deer, fallow deer and brocket deer, the time from implant removal to the onset of estrus ranged from 24 to 58 hours [34, 37-39]. After the first signs of estrus, ovulation occurred in a period between 20 and 26 hours [38, 39]. The observation of mating behavior of our roe deer in 2016 indicates that estrus in roe deer begins one day after progestin implant removal.

Table 2: Embryonic stages collected on day 12 and 13 after natural breeding in 2016. UFO - unfertilized oocyte

\begin{tabular}{|c|c|c|c|c|c|c|}
\hline Animal & UFO & 2-6 cell & Morula & Blastocyst & $\begin{array}{l}\text { Blastocyst } \\
\text { hatched }\end{array}$ & $\begin{array}{l}\text { Total } \\
\text { embryos } \\
\text { per doe }\end{array}$ \\
\hline 1 & - & - & - & - & - & - \\
\hline 2 & - & - & - & 10 & - & 10 \\
\hline 3 & - & - & - & - & - & - \\
\hline 4 & - & - & - & - & - & - \\
\hline 5 & 1 & - & - & 2 & - & 2 \\
\hline 6 & 1 & - & - & 1 & - & 1 \\
\hline 7 & - & - & - & - & - & - \\
\hline 8 & - & - & 2 & 2 & 1 & 5 \\
\hline 9 & - & 1 & 1 & 3 & 1 & 5 \\
\hline 10 & - & - & - & - & - & - \\
\hline 11 & - & 1 & 2 & - & - & 3 \\
\hline 12 & - & - & - & - & - & - \\
\hline 13 & 5 & - & - & - & - & - \\
\hline 14 & 3 & 2 & - & - & - & 2 \\
\hline 15 & - & - & - & - & - & - \\
\hline Total & 10 & 4 & 5 & 18 & 2 & 28 \\
\hline
\end{tabular}


The hormonal treatment of superovulation might have advanced the onset of estrus, LH peak and ovulation. Equine chorionic gonadotropin (eCG), which exhibits both FSH and LH activity, has a long biological half life of up to 40 days in the cow [40]. Its prolonged effect can lead to continuous ovarian stimulation resulting in asynchronous follicular waves [41]. This would be in line with our observations of additional ovulations and subsequent $\mathrm{CL}$ development between the day of $\mathrm{Al}$ and the day of embryo flushing in roe deer. The prolonged effect of eCG can be counterbalanced by the administration of eCG antibodies [42,43], but unfortunately, these are not commercially available anymore. Although both FSH and LH are essential for follicular maturation, endogenous LH seems to be sufficient [44]. In standardized superovulation programs in cattle, generic FSH is employed to stimulate folliculogenesis $[44,45]$. FSH has a short half-life and is administered twice daily over a period of 10 days. This would have been the superior option. However, the practical application is not easily effected in wild species such as the roe deer, because multiple immobilization for hormonal treatment is not desirable. The exact relationship of FSH and LH in crude gonadotropin preparations can vary [46]. The presence of well-developed $C L$ on the day of Al indicates that the LH effect of eCG in our roe deer was more pronounced.

In our study, flushing at day 6 and 7 after Al revealed embryos in the 2- to maximum 12-cell stage in the uterine lumen. In other ruminants, the embryos at that time have reached the blastocyst stage [47]. In superovulated red deer, embryos in the morula and blastocyst stage were collected 8 days after removal of a progesterone releasing device [48]. Accordingly, superovulation and embryo collection 6 days after Al in fallow deer [36], and 7 days after Al in sika deer (Cervus nippon) [49] yielded embryos in the blastocyst stage. These observations in cattle and deer indicate that superstimulation protocols do not inhibit general blastocyst formation. To test whether the finding of the pre-morula stages in our roe deer was due to the negative effects of the hormonal regime, we also performed embryo flushing at days 12 and 13. At this time point, roe deer embryos were mainly in the morula and blastocyst stage, demonstrating that the developmental competence of the embryos was not impaired after superovulation. These results thus point towards a physiological finding. In other artiodactyls such as pig, sheep and cows, embryos have begun to elongate at day 11 [50-52].

Possible adverse effects of the superstimulation protocol on embryo development are difficult to assess since systematic studies in roe deer and other cervids are unavailable. In cattle, ovarian superstimulation is associated with premature maturation and ovulation and reduced competence of oocytes. Blondin et al. [53] have shown that oocytes derived from superovulated cows had a reduced capacity to develop to the 12-cell stage after 5 days in culture. However, these 12-cell stage embryos did not display a reduced competence to further develop to the 32-cell early blastocyst stage after two more days, which is the regular developmental time in vivo. From this finding it can be concluded that the hormonal influence is of such a nature that incompetent oocytes do not develop to embryos at all, but those who are competent develop at a normal pace.

The development of more than 2 or $3 \mathrm{CL}$, which is the physiological state in roe deer, resulted in higher plasma P4 concentrations in superovulated animals than reported for non-stimulated wild roe deer [54]. Elevated P4 did not exert a direct negative effect on blastocyst development prior to hatching in cows [55-57].

Superstimulation is routinely performed in the bovine industry with the production of more than 630,000 transferable embryos per year [58], indicating the general applicability of the superovulation treatment. Superovulation regimes have also been successfully employed in cervid and ovine species $[34,36,59,60]$. The finding of morula and blastocyst stages in other wild ruminants, where superstimulation protocols are derived from the bovine model and have not yet been optimized for the specific species moreover suggests that the roe deer blastocysts collected at days 12 and 13 after breeding represent a physiological condition. 
From our findings we conclude that embryonic growth velocity in the roe deer is already reduced prior to the blastocyst stage. Compared to other deer species and cattle, the expanded blastocyst stage is reached at minimum 4 days and at maximum 7 days later (Fig. 5), suggesting that the extremely decelerated embryonic growth observed during diapause in roe deer is gradually preluded during blastocyst development.

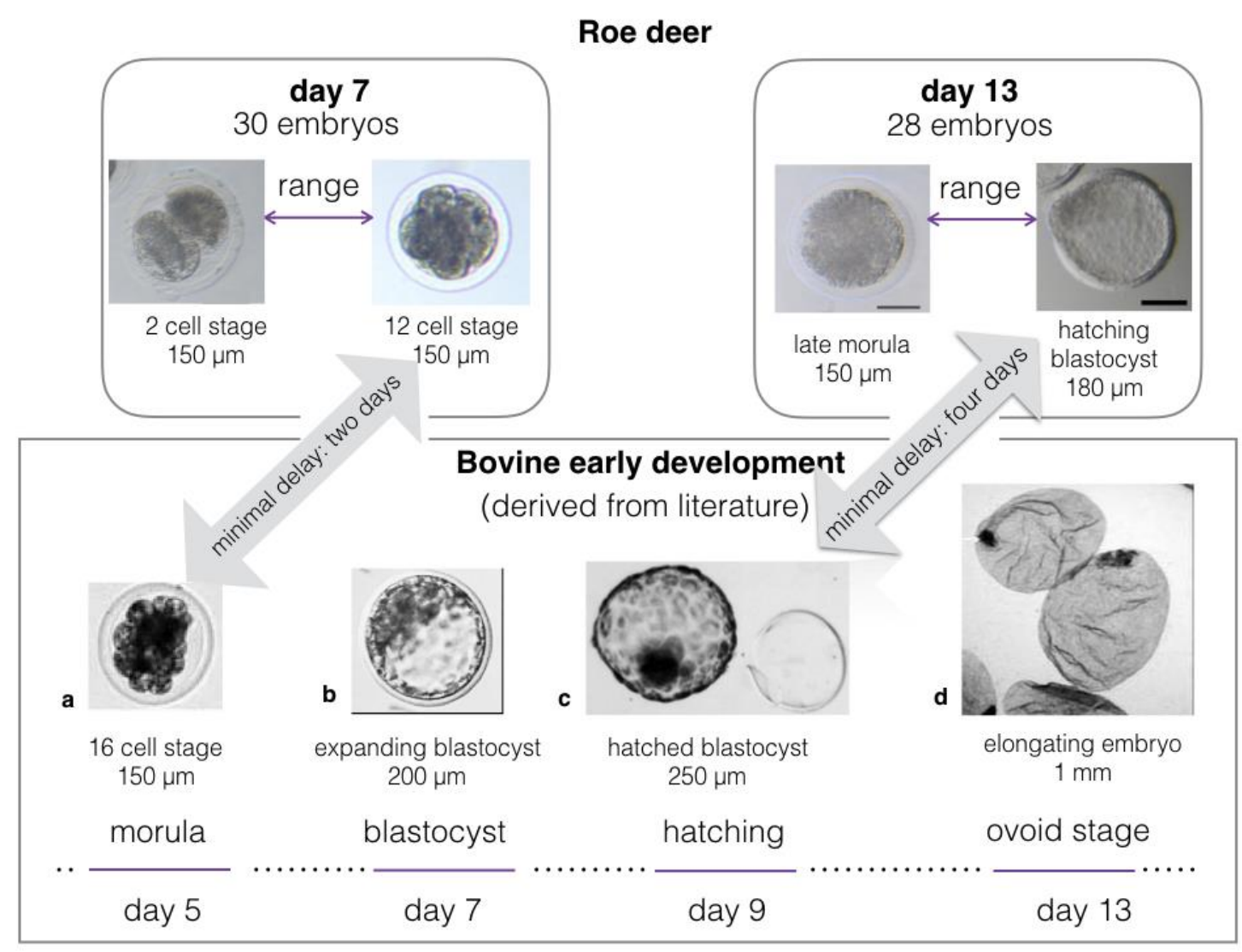

Figure 5. Range of roe deer embryonic stages collected on day 6 and 7 after artificial insemination and days 12 and 13 after natural breeding in comparison with bovine development derived from literature [61, 62]. Scale bar $=50 \mu \mathrm{m}$

Gene expression studies have shown that development to the blastocyst stage shows great similarities between species $[63,64]$. However, the coordination of the cell cycle with morphogenesis and cellular differentiation are so far unclear and the bulk of information concerning cell cycle regulation is derived from frog and zebrafish models [65].

During cleavage, the cell cycle is regulated by oscillating concentrations of maternally derived cyclins [66] resulting in the formation of totipotent blastomeres. Hereby, the gap phases typical for the somatic cell cycle are omitted and cell cycle duration is very short. In the mouse for example, the cell cycle time during cleavage is approximately $12 \mathrm{~h}$ [67] and in the zebrafish $0.5 \mathrm{~h}$ [68]. During that maternally controlled period of embryonic growth, external factors do not influence on cell cycle progression as demonstrated for the zebrafish [65]. Blastocyst formation involves cell differentiation which is accompanied by the introduction of gap phases, especially gap phase 1 , resulting in an elongated cell cycle [69]. This process seems to be coupled with the introduction of external cell-cycle regulation which could act as pacemakers by translating environmental cues such as alterations in photoperiod. The same mechanisms that slow embryonic cell cycle progression and thereby embryo development might be involved in the entry into diapause. We 
hypothesize that in the roe deer, decelerated development in the first days of embryo development are further pronounced during diapause.

In our study we have shown that it is possible to successfully superstimulate roe deer and collect multiple embryos at defined stages of pregnancy. We observed that compared to non-diapausing related cattle and other deer species and also to other species exhibiting diapause, early embryo development in the roe deer is delayed. The roe deer therefore seems to be a promising model to investigate internal and external cell cycle cues regulating embryonic growth.

\section{Declaration of interest}

The authors declare that there is no conflict of interests.

\section{Funding}

The study was funded by the Swiss National Science Foundation SNSF (31003A_159734).

\section{Acknowledgements}

We gratefully acknowledge the dedicated work in roe deer care and handling of the personnel at the field research station of the IZW; namely Jurek and Irina Kasprzak, Janina Radwainski and Ervin Havic. Further we like to thank Johanna Painer, Robert Hermes, Joseph Saragusty, Janina Radwainski, Ursula Taeubenbacher and Emanuela Gatto for their professional assistance during the veterinary procedures. Nga Nguyen and Jette Ziep were a great help in providing technical support.

\section{References}

[1] Artus J, Babinet C and Cohen-Tannoudji M. 2006 The cell cycle of early mammalian embryos: lessons from genetic mouse models. Cell cycle 5(5) 499-502.

[2] Adjaye J, Huntriss J, Herwig R, BenKahla A, Brink TC, Wierling C, Hultschig C, Groth D, Yaspo ML, Picton HM, Gosden RG and Lehrach H. 2005 Primary differentiation in the human blastocyst: Comparative molecular portraits of inner cell mass and trophectoderm cells. Stem Cells 23(10) 1514-1525.

[3] Watson AJ and Barcroft LC. 2001 Regulation of blastocyst formation. Front Biosci 6 708-730.

[4] Ellington JE, Farrell PB and Foote RH. 1990 Comparison of six-day bovine embryo development in uterine tube (oviduct) epithelial cell co-culture versus in vivo development in the cow. Theriogenology 34(5) 837-844.

[5] Murillo A, Muñoz M, Martín-González D, Carrocera S, Martínez-Nistal A and Gómez E. 2017 Low serum concentration in bovine embryo culture enhances early blastocyst rates on Day- 6 with quality traits in the expanded blastocyst stage similar to BSA-cultured embryos. Reproductive Biology 17(2) 162-171.

[6] Desmarais JA, Bordignon V, Lopes FL, Smith LC and Murphy BD. 2004 The escape of the mink embryo from obligate diapause. Biology of Reproduction 70(3) 662-670.

[7] Renfree MB and Lewis AM. 1996 Cleavage in vivo and in vitro in the marsupial Macropus eugenii. Reprod Fertil Develop 8(4) 725-42.

[8] Smith MJ. 1981 Morphological observations on the diapausing blastocyst of some macropodid marsupials. Journal of Reproduction and Fertility 61(2) 483-\&.

[9] Tyndale-Biscoe CH and Renfree MB. 1987 Reproductive Physiology of Marsupials. Cambridge: Cambridge University Press.

[10] Aitken RJ. 1981 Aspects of delayed implantation in the roe deer (Capreolus capreolus). Journal of Reproduction and Fertility. Supplement 29 83-95. 
[11] Aitken RJ. 1974 Delayed implantation in roe deer (Capreolus capreolus). Journal of Reproduction and Fertility 39(1) 225-33.

[12] Short RV and Hay MF. Delayed implantation in the roe deer (Capreolus capreolus). in Symposium of the Zoological Society of London. 1966.

[13] Aitken RJ. 1975 Ultrastructure of the blastocyst and endometrium of the roe deer (Capreolus capreolus) during delayed implantation. J Anat 119(Pt 2) 369-84.

[14] Aitken RJ, Burton J, Hawkins J, Kerrwils.R, Short RV and Steven DH. 1973 Histological and Ultrastructural Changes in Blastocyst and Reproductive Tract of Roe Deer, Capreolus-Capreolus, during Delayed Implantation. Journal of Reproduction and Fertility 34(3) 481-\&.

[15] Lambert RT, Ashworth CJ, Beattie L, Gebbie FE, Hutchinson JS, Kyle DJ and Racey PA. 2001 Temporal changes in reproductive hormones and conceptus-endometrial interactions during embryonic diapause and reactivation of the blastocyst in European roe deer (Capreolus capreolus). Reproduction 121(6) 863-71.

[16] Lengwinat T and Meyer HH. 1996 Investigations of BrdU incorporation in roe deer blastocysts in vitro. Animal Reproduction Science 45(1-2) 103-7.

[17] Bischoff TLW, Entwicklungsgeschichte des Rehes. 1854, Rickersche Buchhandlung: Gießen.

[18] Keibel F. 1902 Die Entwicklung des Rehes bis zur Anlage des Mesoblast. Arch. Anat. Physiol. Suppl.: 292-314.

[19] Fenelon JC, Shaw G, Frankenberg SR, Murphy BD and Renfree MB. 2017 Embryo arrest and reactivation: potential candidates controlling embryonic diapause in the tammar wallaby and mink. Biology of Reproduction 96(4) 877-894.

[20] Murphy BD, Concannon PW, Travis HF and Hansel W. 1981 Prolactin - the Hypophyseal Factor That Terminates Embryonic Diapause in Mink. Biology of Reproduction 25(3) 487-491.

[21] Stoufflet I, Mondainmonval M, Simon P and Martinet L. 1989 Patterns of Plasma Progesterone, Androgen and Estrogen Concentrations and Invitro Ovarian Steroidogenesis during Embryonic Diapause and Implantation in the Mink (Mustela-Vison). Journal of Reproduction and Fertility 87(1) 209-221.

[22] Baevsky U. 1963 The effect of embryonic diapause on the nuclei and mitoti activity of mink and rat blastocysts, in Delayed Implantation, A Enders, Editor. University of Chicago Press: Chicago. 141-153.

[23] Berger PJ and Sharman GB. 1969 Progesterone-induced development of dormant blastocysts in the tammar wallaby, Macropus eugenii Desmarest; Marsupialia. Journal of Reproduction and Fertility 20(2) 20110.

[24] Daniel JCJ. 1967 Studies on the growth of the mink blastocyst. J Embryol exp Morph 17(2) 293-302.

[25] Frankenberg SR, de Barros FR, Rossant J and Renfree MB. 2016 The mammalian blastocyst. Wiley Interdiscip Rev Dev Biol 5(2) 210-32.

[26] Murphy BD. 2012 Embryonic diapause: advances in understanding the enigma of seasonal delayed implantation. (1439-0531 (Electronic)).

[27] Renfree MB and Shaw G. 2000 Diapause. Annual Review of Physiology 62 353-375.

[28] Peppler RD and Stone SC. 1980 Plasma Progesterone Level during Delayed Implantation, Gestation and Postpartum Period in the Armadillo. Laboratory Animal Science 30(2) 188-191.

[29] Goeritz F, Quest M, Wagener A, Fassbender M, Broich A, Hildebrandt TB, Hofmann RR and Blottner S. 2003 Seasonal timing of sperm production in roe deer: interrelationship among changes in ejaculate parameters, morphology and function of testis and accessory glands. Theriogenology 59(7) 1487-1502.

[30] Gardner DK and Lane M. 2002 Development of viable mammalian embryos in vitro: evolution of sequential media, ed. R Cibelli, K Lanza, AK Campbell, and MD West. Vol. 187. San Diego, Academic Press.

[31] Baczkowski T, Kurzawa R and Glabowski W. 2004 Methods of embryo scoring in in vitro fertilization. Reprod Biol 4(1) 5-22.

[32] Prakash BS, Meyer HHD, Schallenberger E and van De Wiel DFM. 1987 Development of a sensitive enzymeimmunoassay (EIA) for progesterone determination in unextracted bovine plasma using the second antibody technique. Journal of Steroid Biochemistry 28(6) 623-627. 
[33] Drews B, Vegas AR, van der Weijden VA, Milojevic V, Hankele AK, Schuler G and Ulbrich SE. 2019 Do ovarian steroid hormones control the resumption of embryonic growth following the period of diapause in roe deer (Capreolus capreolus)? Reproductive Biology 19(2) 149-157.

[34] Zanetti ES, Munerato MS, Cursino MS and Duarte JM. 2014 Comparing two different superovulation protocols on ovarian activity and fecal glucocorticoid levels in the brown brocket deer (Mazama gouazoubira). Reprod Biol Endocrinol 1224.

[35] Asher GW, Fisher MW, Fennessy PF, Mackintosh CG, Jabbour HN and Morrow CJ. 1993 Oestrous synchronization, semen collection and artificial insemination of farmed red deer (Cervus elaphus) and fallow deer (Dama dama). Animal Reproduction Science 33(1) 241-265.

[36] Morrow CJ, Asher GW, Berg DK, Tervit HR, Pugh PA, Mcmillan WH, Beaumont S, Hall DRH and Bell ACS. 1994 Embryo-Transfer in Fallow Deer (Dama-Dama) - Superovulation, Embryo Recovery and Laparoscopic Transfer of Fresh and Cryopreserved Embryos. Theriogenology 42(4) 579-590.

[37] Asher GW, Fisher MW, Fennessy PF, Mackintosh CG, Jabbour HN and Morrow CJ. 1993 Estrous Synchronization, Semen Collection and Artificial-Insemination of Farmed Red Deer (Cervus-Elaphus) and Fallow Deer (Dama-Dama). Animal Reproduction Science 33(1-4) 241-265.

[38] Asher GW, Fisher MW, Jabbour HN, Smith JF, Mulley RC, Morrow CJ, Veldhuizen FA and Langridge M. 1992 Relationship between the onset of oestrus, the preovulatory surge in luteinizing hormone and ovulation following oestrous synchronization and superovulation of farmed red deer (Cervus elaphus). Journal of Reproduction and Fertility 96(1) 261-73.

[39] Asher GW, Fisher MW, Smith JF, Jabbour HN and Morrow CJ. 1990 Temporal Relationship between the Onset of Estrus, the Preovulatory LH Surge and Ovulation in Farmed Fallow Deer, Dama-Dama. Journal of Reproduction and Fertility 89(2) 761-767.

[40] Murphy BD and Martinuk SD. 1991 Equine chorionic gonadotropin. Endocrine Reviews 12(1) 27-44.

[41] Gonzalez-Reyna A, Marquez-Garcia E, Lizarraga-Tracy H and Martinez-Gonzalez JC. 1999 Dose response effects of PMSG on ovulation rate and follicular development in Pelibuey ewes treated with Syncro-mate-B implants. Small Ruminant Research 31(2) 149-155.

[42] Dieleman SJ, Bevers MM, Wurth YA, Gielen JT and Willemse AH. 1989 Improved Embryo Yield and Condition of Donor Ovaries in Cows after Pmsg Superovulation with Monoclonal Anti-Pmsg Administered Shortly after the Preovulatory Lh Peak. Theriogenology 31(2) 473-487.

[43] Gonzalez A, Wang H, Carruthers TD, Murphy BD and Mapletoft RJ. 1994 Increased Ovulation Rates in Pmsg-Stimulated Beef Heifers Treated with a Monoclonal Pmsg Antibody. Theriogenology 41(8) 1631-1642.

[44] Looney CR, Bondioli KR, Hill KG and Massey JM. 1988 Superovulation of Donor Cows with Bovine Follicle-Stimulating-Hormone (Bfsh) Produced by Recombinant DNA Technology. Theriogenology 29(1) 271271.

[45] Hasler JF, Mccauley AD, Schermerhorn EC and Foote RH. 1983 Superovulatory Responses of Holstein Cows. Theriogenology 19(1) 83-99.

[46] Mapletoft RJ, Steward KB and Adams GP. 2002 Recent advances in the superovulation in cattle. Reproduction Nutrition Development 42(6) 601-611.

[47] Guillomot M. 1995 Cellular Interactions during Implantation in Domestic Ruminants. Journal of Reproduction and Fertility 39-51.

[48] Fennessy PF, Fisher MW, Shackell GH and Mackintosh CG. 1989 Superovulation and Embryo Recovery in Red Deer (Cervus-Elaphus) Hinds. Theriogenology 32(5) 877-883.

[49] Wang L, Zhuo Z-Y, Shi W-Q, Tan D-X, Gao C, Tian X-Z, Zhang L, Zhou G-B, Zhu S-E, Yun P and Liu G-S. 2014 Melatonin Promotes Superovulation in Sika Deer (Cervus nippon). International Journal of Molecular Sciences 15(7) 12107.

[50] Betteridge KJ and Fléchon JE. 1988 The anatomy and physiology of pre-attachment bovine embryos. Theriogenology 29(1) 155-187.

[51] Brooks K, Burns G and Spencer TE. 2014 Conceptus elongation in ruminants: roles of progesterone, prostaglandin, interferon tau and cortisol. Journal of Animal Science and Biotechnology 5.

[52] Heuser CH and Streeter GL. 1929 Early stages in the development of pig embryos, from the period of initial cleavage to the time of the appearance of limb-buds. Contributions to embryology 20 3-29. 
[53] Blondin P, Coenen K, Guilbault LA and Sirard MA. 1996 Superovulation can reduce the developmental competence of bovine embryos. Theriogenology 46(7) 1191-1203.

[54] Drews B, Rudolf Vegas A, van der Weijden VA, Milojevic V, Hankele AK, Schuler G and Ulbrich SE. 2019 Do ovarian steroid hormones control the resumption of embryonic growth following the period of diapause in roe deer (Capreolus capreolus)? Reprod Biol 19(2) 149-157.

[55] Carter F, Forde N, Duffy P, Wade M, Fair T, Crowe MA, Evans ACO, Kenny DA, Roche JF and Lonergan P. 2008 Effect of increasing progesterone concentration from Day 3 of pregnancy on subsequent embryo survival and development in beef heifers. Reproduction Fertility and Development 20(3) 368-375.

[56] Carter F, Rings F, Mamo S, Holker M, Kuzmany A, Besenfelder U, Havlicek V, Mehta JP, Tesfaye D, Schellander K and Lonergan P. 2010 Effect of Elevated Circulating Progesterone Concentration on Bovine Blastocyst Development and Global Transcriptome Following Endoscopic Transfer of In Vitro Produced Embryos to the Bovine Oviduct. Biology of Reproduction 83(5) 707-719.

[57] Larson JE, Krisher RL and Lamb GC. 2011 Effects of supplemental progesterone on the development, metabolism and blastocyst cell number of bovine embryos produced in vitro. Reproduction Fertility and Development 23(2) 311-318.

[58] Perry G. 20182016 Statistics of Embryo Collection and Transfer in Domestic Farm Animals.

[59] Santiago-Moreno J, Gonzalez-Bulnes A, Gomez-Brunet A, Cocero MJ, del Campo A, Garcia-Garcia R and Lopez-Sebastian A. 2001 Procedure for successful interspecific embryo transfer from mouflon (Ovis gmelini musimon) to Spanish Merino Sheep (Ovis aries). Journal of Zoo and Wildlife Medicine 32(3) 336-341.

[60] Andrabi SM and Maxwell WM. 2007 A review on reproductive biotechnologies for conservation of endangered mammalian species. Animal Reproduction Science 99(3-4) 223-43.

[61] Jahnke Marianna M, West James K and Youngs Curtis R. 2014 Evaluation of In Vivo-Derived Bovine Embryos. Bovine Reproduction.

[62] Lonergan P, Woods A, Fair T, Carter F, Rizos D, Ward F, Quinn K and Evans A. 2007 Effect of embryo source and recipient progesterone environment on embryo development in cattle. Reprod Fertil Dev 19(7) 861-8.

[63] Adjaye J, Herwig R, Brink TC, Herrmann D, Greber B, Sudheer S, Groth D, Carnwath JW, Lehrach H and Niemann H. 2007 Conserved molecular portraits of bovine and human blastocysts as a consequence of the transition from maternal to embryonic control of gene expression. Physiological Genomics 31(2) 315327.

[64] Daigneault BW, Rajput S, Smith GW and Ross PJ. 2018 Embryonic POU5F1 is Required for Expanded Bovine Blastocyst Formation. Scientific Reports 8(1) 7753.

[65] Siefert JC, Clowdus EA and Sansam CL. 2015 Cell Cycle Control in the Early Embryonic Development of Aquatic Animal Species. Comparative biochemistry and physiology. Toxicology \& pharmacology : CBP 178 8-15.

[66] Nixon VL, Levasseur M, McDougall A and Jones KT. 2002 Ca2+ oscillations promote APC/Cdependent cyclin $\mathrm{B} 1$ degradation during metaphase arrest and completion of meiosis in fertilizing mouse eggs. Current Biology 12(9) 746-750.

[67] Thouas GA, Korfiatis NA, French AJ, Jones GM and Trounson AO. 2001 Simplified technique for differential staining of inner cell mass and trophectoderm cells of mouse and bovine blastocysts. Reproductive BioMedicine Online 3(1) 25-29.

[68] Hörmanseder E, Tischer T and Mayer Thomas U. 2013 Modulation of cell cycle control during oocyte-to-embryo transitions. The EMBO Journal 32(16) 2191-2203.

[69] Li VC and Kirschner MW. 2014 Molecular ties between the cell cycle and differentiation in embryonic stem cells. Proceedings of the National Academy of Sciences 111(26) 9503. 


\section{Audience Discussion}

Bruce Murphy: In the roe deer, it seems like it goes into diapause slowly and then it begins to exit and continues developing, so do you think we can still define what happens in the roe deer as a classic diapause situation or is it simply slowly doing all the diapause things, but just doing them more slowly?

Barbara Drews: This is what we had hypothesised - that it is a transient process and it's more like a time-lapse, really slow motion development which might really differ from other situations.

Unknown questioner: In some other species, hCG has been shown to alter the uterine environment and many experimenters have switched LH for ovulation induction. Do you think that there might have been some deleterious influence of hCG; and do you propose to apply a different ovulation induction protocol for comparison? The uterine environment is particularly important in diapause, and hCG has been shown in other species to not be the best ovulation induction. Should this be further investigated?

Barbara Drews: Our protocols have been implemented before and were shown to be efficient in our species, so we didn't want to modify. But I think you made a good point and I think if we ever repeat these experiments we will think about $\mathrm{LH}$ as well. 